\title{
APASL practical recommendations for the management of hepatocellular carcinoma in the era of COVID-19
}

\author{
Shuichiro Shiina ${ }^{1}$ - Rino A. Gani ${ }^{2} \cdot$ Osamu Yokosuka $^{3} \cdot$ Hitoshi Maruyama $^{1} \cdot$ Hiroaki Nagamatsu' ${ }^{1}$. \\ Diana Alcantara Payawal ${ }^{4}$. A. Kadir Dokmeci ${ }^{5} \cdot$ Laurentius A. Lesmana $^{6} \cdot$ Tawesak Tanwandee $^{7} \cdot$ George Lau $^{8,9}$. \\ Shiv Kumar Sarin ${ }^{10} \cdot$ Masao Omata ${ }^{11,12}$
}

Received: 8 June 2020 / Accepted: 22 October 2020 / Published online: 11 November 2020

(c) The Author(s) 2020

\begin{abstract}
Background COVID-19 has been giving the devastating impact on the current medical care system. There are quite many guidelines on COVID-19, but only a few on the management of hepatocellular carcinoma (HCC) during COVID-19 pandemic. Aims We develop these recommendations to preserve adequate clinical practice for the management of HCC.

Methods Experts of HCC in the Asia-Pacific region exchanged opinions via webinar, and these recommendations were formed.

Results Close contact should be minimized to reduce possible exposure of both medical staff and patients to the novel coronavirus. To prevent transmission of the virus, meticulous hygiene measures are important. With the decrease in regular medical service, the medical staff may be mobilized to provide COVID-19-related patient care. However, diagnosis and treatment of HCC should not be delayed because of COVID-19 pandemic. The management of HCC should be the same as in non-pandemic circumstances. HCC is highly malignant, thus it is recommended not to delay curative treatment such as surgery and ablation. However, a kind of triage is necessary even among patients with HCC when resources are insufficient for all to be treated. Curative treatments should be periodized and cytoreductive or non-curative treatment such as vascular interventions and systemic therapy may be postponed until it can be performed safely with sufficient resources. For patients with confirmed or suspected to be infected with the novel coronavirus, diagnosis and treatment should be postponed until the virus is eliminated or they are confirmed as not being infected with it.

Conclusions These are collection of measures implemented by front-line medical professionals. We would evolve these recommendations over time as more real-world data becomes available.
\end{abstract}

Keywords The novel coronavirus · Liver cancer - Asian-Pacific · Chronic liver disease - Asymptomatically infected . Hospital preparedness · Surveillance · Diagnosis · Facemask · CT screening for COVID-19 · Treatment · Decision-making · Personal protective equipment $\cdot$ Aerosol generating procedure

$\begin{array}{ll}\text { Abbreviations } \\ \text { COVID-19 } & \text { Coronavirus disease 2019 } \\ \text { PPE } & \text { Personal protective equipment } \\ \text { HCC } & \text { Hepatocellular carcinoma } \\ \text { HBV } & \text { Hepatitis B virus } \\ \text { HCV } & \text { Hepatitis C virus } \\ \text { CDC } & \text { Centers for Disease Control and Prevention } \\ \text { US } & \text { Ultrasound } \\ \text { AFP } & \text { Alpha-fetoprotein }\end{array}$

Shuichiro Shiina

sshiina@juntendo.ac.jp

Extended author information available on the last page of the article

\section{Introduction}

Coronavirus disease 2019 (COVID-19), an infectious disease caused by the novel coronavirus (SARS-CoV-2) has brought upon devastating stress on the current medical care system. The World Health Organization (WHO) recognized the outbreak of COVID-19 as a pandemic on 11 March 2020. As of 19th Aug 2020, COVID-19 pandemic has resulted in over 21.9 million confirmed cases globally, and over 775 thousand deaths. Approximately 250 thousand newly-confirmed cases are being reported daily. The pandemic has not settled down yet [1]. The virus is mainly transmitted from personto-person through respiratory droplets and contact with contaminated surfaces or objects. There are also other modes of 
transmission (i.e. airborne and fecal-oral). The average incubation period is 5-6 days, ranging from 0 to 14 days. The clinical spectrum of COVID-19 ranges from mild disease with non-specific signs and symptoms of acute respiratory illness to severe pneumonia with respiratory failure and septic shock. There are also reports of asymptomatic cases. Currently, there is no vaccine against the novel coronavirus. The best way to prevent COVID-19 is to avoid being exposed to the coronavirus. It is recommended that we should keep distance of at least $2 \mathrm{~m}$ from other people. A new modeling study shows that intermittent periods of social distancing strategies will be needed till 2022 to avoid overloading of the medical system with its limited critical care capacity [2].

Until the end of this COVID-19 pandemic, one needs to maintain high management standards of other diseases despite the shortage of medical resources, such as personnel, beds, personal protective equipment (PPE) and ventilators. There are a number of guidelines and recommendations on COVID-19 [3-5]. However, there are only few guidelines and recommendations on the management of hepatocellular carcinoma (HCC) on pandemic of COVID-19 [6, 7].

Currently, liver cancer is the fourth most common cause of cancer-related death in the world, which caused 782 thousand deaths in 2018 [8]. More than $90 \%$ of liver cancer is hepatocellular carcinoma (HCC). The majority of cases of HCC are found in the Asian-Pacific region [9]. Since Asia-pacific region has more experience both in $\mathrm{HCC}$ and in COVID-19 than anywhere else, experts of HCC exchanged opinions via webinar and developed these recommendations to preserve and sustain adequate clinical practice in the management of HCC in the era of COVID-19.

APASL has presented clinical practice guidance for general hepatology and liver transplant providers during the COVID-19 pandemic which also includes HCC [10]. Our article focuses specifically on HCC, presents more practical recommendations and elaborates on the different management needs. Our article does not have either grading of evidence or grading of recommendation as well as many recommendations concerning COVID-19 [3-7, 11]. Since COVID-19 is a novel disease, guidance by scientific evidence is rarely available. The recommendations are the collection of measures implemented by front-line medical professionals and are revised through intense interaction via webinar. The presenter, the moderators and co-authors exchanged opinions and discussed the contents via emails and phones. These recommendations are likely to evolve over time as further data become available.

\section{COVID-19 and cancer}

Patients with cancer seem to be easier to be infected with the novel coronavirus than individuals without cancer. A prospective study in China revealed that 18 (1\%) of 1590 COVID-19 patients had a history of cancer, which seems to be higher than the incidence of cancer in the overall Chinese population [12]. They are also likely to be at an increased risk of progression to severe diseases with COVID-19, such as being admitted to the intensive care unit requiring invasive ventilation, and death, compared with patients without cancer. A retrospective study in Wuhan, China reported that $12(0.79 \%)$ of 1524 patients with COVID-19 had cancer. It revealed that patients with cancer from the epicenter of COVID-19 had a higher risk of the novel coronavirus infection compared with the general population. Seven $(58.3 \%)$ of 12 patients had non-small cell lung cancer [13]. In a different retrospective study, there were 28 patients with cancer who were admitted for COVID-19 in three hospitals in Wuhan and who had received cancer therapy within 14 days. They were found to be associated with substantially higher risk of mortality [14]. Patients with cancer may be susceptible to the infection and more likely to have higher morbidity and mortality than the general population. Several factors could account for an elevated risk for the infection and consequent complications among cancer patients, including systemic immunocompromised state caused by the malignancy and anticancer treatments, frequent hospital visits, advanced age, and poor performance status.

Cancer is the second leading cause of death. An estimated 9.6 million people died of cancer globally in 2018, i.e., about 1 in 6 deaths was due to cancer. The five most common causes of cancer death were cancers of lung (1.76 million deaths), colorectal (862 thousand deaths), stomach (783 thousand deaths), liver (782 thousand deaths) and breast (627 thousand deaths) [8].

Cancer mortality can be reduced if cases are detected and treated without delay. When detected early, cancer is more likely to respond to effective treatment and can result in a greater probability of surviving, less morbidity, and less expensive treatment. Significant improvements can be made in the lives of cancer patients by detecting cancer early and avoiding delays in treatment. We should not delay the diagnosis and treatment of cancer in the era of COVID19 pandemic. However, it would be necessary to tailor the management depending on available resources. Indication of any invasive procedure should be decided on a case-by-case basis with the consideration of the increased risk during the pandemic, the urgency of the procedure and the effect of the delayed intervention. 


\section{COVID-19 and chronic liver disease}

Most patients with HCC have underlying chronic liver disease, resulting from chronic hepatitis B virus (HBV) or chronic hepatitis $\mathrm{C}$ virus (HCV) infection, alcoholic liver disease, and non-alcoholic fatty liver disease. There have not been sufficient data on whether patients with chronic liver disease are at increased risk for getting COVID-19 or having severe COVID-19 [15]. CDC COVID-19 Response Team reported that 2692 (37.6\%) of 7162 patients with full past history of illness had one or more underlying health condition or risk factor. They also reported that $41(0.6 \%)$ had chronic liver disease, 17 (41\%) of whom were hospitalized and 7 (17\%) were treated in ICU [16]. Incidentally, the most commonly reported conditions were diabetes mellitus, chronic lung disease, and cardiovascular disease. In other series of COVID-19 reported by Chinese centers, $2-11 \%$ of patients had comorbid chronic liver disease [16-22]. There is a report that patients with non-alcoholic fatty liver disease were associated with COVID-19 progression [23].

Infection with the novel coronavirus may impact existing chronic liver disease in three ways: first, the additional hepatic injury induced by COVID-19 could lead to hepatic decompensation in patients with compromised hepatic reserves [24]. Second, the potential immunosuppressive properties induced by the novel coronavirus may lead to viral reactivation in patients with chronic viral hepatitis, although more data are required to confirm this hypothesis [24, 25]. Third, drugs used for the treatment of COVID-19 may produce hepatotoxicity, as suggested by histological features of moderate microvascular steatosis with mild hepatic inflammation [26, 27]. Many patients had antipyretic drugs for fever. Most antipyretic drugs contain acetaminophen, which has direct hepatotoxic potential. Furthermore, many patients with COVID-19 may be treated with novel, potentially hepatotoxic, antiviral drugs as well as antibiotics for bacterial superinfections.

\section{Hospital preparedness for COVID-19}

It is important to minimize exposure of both medical staff and patients to the novel coronavirus. Face-to-face consultation should be performed through web consultation or by telephone call whenever possible. Hospitals should adapt strategies for patients to minimize hospital visits and hospitalization. Routine follow-up visit of hospitals should be postponed as long as possible. If circumstances allow, the appointment registration system should be adapted. Pre-reception inspection should be set up including body temperature check and Questionnaire (symptoms, recent history of close contact with confirmed or suspected person infected with the novel coronavirus). It is important to maintain social safety distance of $2 \mathrm{~m}$ between individuals. In general, hospitals should not allow patients to be accompanied with others because they can be asymptomatically infected with the virus.

There are various ways to screen individuals infected with the novel coronavirus. Reverse transcription polymerase chain reaction (RT-PCR) is the current standard test for COVID-19. In well-equipped hospitals, PCR assays have been conducted a few days prior to admission. Antigen test is another method of detecting the presence of the virus itself. Although it is less accurate, it offers results in about $15 \mathrm{~min}$ as opposed to hours for PCR. Both methods need a cumbersome swab to take samples from the cavity between the nose and mouth (nasopharyngeal swab). Another method is detection of antibodies (serological tests). Antibody tests show how many people have had the disease, including those whose symptoms are minor or who are asymptomatic. The serum antibody rises to certain level at an early period in patients infected with the virus.

In general, chest $\mathrm{CT}$ is not recommended for detecting the novel coronavirus infection. CT should only be deployed in very specific conditions. One is in patients who have high risk of the novel coronavirus infection [26], because the sensitivity of PCR is not $100 \%$. Another condition is in patients who are scheduled to be hospitalized and have abdominal $\mathrm{CT}$, because it is not troublesome to take chest scan simultaneously. Chest CT screening for COVID-19 has a low pick up rate in asymptomatic patients infected with the novel coronavirus and a $20 \%$ false negative rate in symptomatic patients [26, 27]. Radiologic findings in COVID-19 are not specific. Typical features on CT initially include bilateral multilobar ground-glass opacities with a peripheral or posterior distribution.

\section{COVID-19 and HCC}

Generally, the diagnosis and treatment of HCC, which is a highly malignant tumor, should not be delayed because of pandemic of COVID-19. The indications and principles of management of HCC should be the same as in non-pandemic circumstances. However, a kind of triage may be necessary even among patients with HCC when resources are insufficient. With the decrease in regular medical service, staff may be mobilized to provide COVID-19-related patient care. This shift of staff should not have a negative impact on the ability to manage $\mathrm{HCC}$ patients.

Patients with HCC who have symptoms suggestive of COVID-19 or other conditions of high risk of the novel coronavirus infection, such as close contact with infected people or people who come from a severely affected area, and have 
not been tested should undergo PCR. If available, chest CT should also be performed for those who have high risk of the novel coronavirus infection [17, 20, 22]. For patients with confirmed or suspected to be infected with the novel coronavirus, diagnosis and treatment of HCC should be postponed until the virus is eliminated or they are confirmed as not being infected with it. It is supposed that the median time from onset to clinical recovery is approximately 2 weeks for mild cases and is $3-6$ weeks for severe or critical disease cases.

\section{Surveillance for HCC}

Generally, surveillance with ultrasound (US) and serum alpha-fetoprotein (AFP) measurement are undertaken in high-risk groups of patients, such as those with chronic HBV or HCV hepatitis and those with liver cirrhosis of any etiology. US is widely practiced for surveillance of HCC since US is noninvasive and its cost is reasonable. However, in the era of COVID-19, surveillance using US should be limited because of the close contact with patients and US practitioner [28, 29].

Under normal circumstances, a 6-month surveillance interval is considered as a standard for high-risk subjects [30]. Since COVID-19 decreases the regular medical service, it would be necessary to prioritize surveillance of super high-risk patients of developing HCC, such as those with $\mathrm{HBV}$ - or HCV-related liver cirrhosis.

\section{Diagnosis for HCC}

\section{General principles in the era of COVID-19}

In the era of COVID-19 pandemic, the diagnosis of cancers as well as other diseases would not work smoothly in many hospitals because of their limited capacity. However, the diagnosis of HCC should be prioritized because HCC is highly malignant. Every patient should be considered as possibly infected with the novel coronavirus. Table 1 summarizes recommendations for general principles and each examination for HCC.

\section{US}

It is recommended to limit the usage of US, since US practitioners are in close contact with patients [28, 29]. Contrastenhanced US, which is very sensitive to detect hypervascularity in a nodule, should also be limited. As a protection for both US practitioners and patients, surgical facemasks are necessary for US practitioners. Examinees are also advised to wear facemasks. When examinees do not wear masks, US practitioners should have eye guards. Every patient should be considered as possibly infected with the novel coronavirus. To prevent transmission of the virus, meticulous hygiene measures are important. After each examination, thorough cleaning of a gel bottle and all touched surfaces should be performed using a disinfectant $[28,29]$.

\section{CT and MRI}

In general, dynamic CT, dynamic MRI, or gadolinium ethoxybenzyl diethylenetriamine pentaacetic acid ( $\mathrm{Gd}-$ EOBDTPA)-enhanced MRI is recommended as a first-line diagnostic tool for HCC when a screening US shows a possible HCC nodule [30]. As every patient possibly infected with the novel coronavirus, those who have an abdominal $\mathrm{CT}$ in their investigation may also have chest $\mathrm{CT}$ scan at the same time [31]. It would not be troublesome to take chest scan additionally.

However, chest CT should only be deployed in very specific circumstances, because CT screening for COVID-19 has a low pick up rate in asymptomatic patients infected with the novel coronavirus and a $20 \%$ false negative rate in symptomatic patients [26, 27].

After each examination, deep cleaning of equipment, surfaces and contact points is mandatory [32]. If possible,

Table 1 Recommendations for diagnosis of hepatocellular carcinoma during COVID-19 pandemic

\begin{tabular}{ll}
\hline Interventions & Recommendations \\
\hline General principles & The diagnosis of HCC should be prioritized \\
& $\begin{array}{l}\text { Every patient should be considered as possibly infected with the novel coronavirus } \\
\text { For patients with confirmed or suspected to be infected with the novel coronavirus, diagnosis should } \\
\text { be postponed until the virus is eliminated or they are confirmed as not being infected }\end{array}$ \\
& Usage of US should be limited \\
US practitioners should wear surgical facemasks & Examinees are also advised to wear facemasks \\
Ultrasound (US) & When examinees do not wear masks, US practitioners should also have eye guards \\
& In general, chest CT should not be deployed for screening of COVID-19 \\
CT and MRI & Equipment, surfaces and contact points should be deeply cleaned after each examination \\
&
\end{tabular}


establishment of a COVID-19 dedicated CT and/or MRI scanner can minimize the risk of hospital-acquired infection.

\section{Treatment for HCC}

\section{General principles}

We need to decide whether we should perform, postpone or suspend treatment for each individual case by considering the situation in real time not only from medical but also from logistical viewpoint. Telemedicine is important in multi-disciplinary decision-making process on treatment and care plans. This technology would make it possible for HCC patients to get the right treatment at the right time without delay.

HCC as well as most other cancers are considered as progressive diseases, thus it is recommended not to delay their curative treatment such as surgery and ablation. American College of Surgeons recommends Elective Surgery Acuity Scale [33], which would be useful to assist the decisionmaking process not only of surgery but also of other actions to triage non-emergent interventions. $\mathrm{HCC}$ as well as most other cancers may be categorized as "Tier 3a (high acuity)", thus action should not be postponed in general. However, a kind of triage is necessary even among patients with HCC when resources are insufficient for all to be treated without delay. Curative treatments should be more prioritized and cytoreductive or non-curative treatments may be postponed until they can be performed safely. The situation may be different from country to country and from institution to institution.

During the intervention, minimum number of staff should be in the room and all staff in the room should wear appropriate PPE [34] depending on their role and risk. In some interventions without aerosol generation, PPE may be necessary only for operators who have close contact with patients possibly infected with the novel coronavirus. Procedure tasks are slower and more difficult when wearing full PPE [35]. Table 2 summarizes recommendations on general principles and each treatment for HCC.

\section{Liver resection}

Liver resection (LR) is a curative treatment for $\mathrm{HCC}$ among Child-Pugh class A patients, although recurrence develops in most cases even after radical resection. Its indication should be decided based on not only tumor condition but also liver function. Generally, liver resection with curative intent should not be delayed. However, in cases of high risk of decompensation or comorbidities that increase risk of severe COVID-19, surgical intervention should be postponed or alternative therapy such as ablation should be adapted.

Table 2 Recommendations for treatment of hepatocellular carcinoma during COVID-19 pandemic

\begin{tabular}{|c|c|}
\hline Interventions & Recommendations \\
\hline General principles & $\begin{array}{l}\text { Whether to perform, postpone or suspend treatment should be decided for each individual case not only from medical } \\
\text { but also from logistical viewpoint } \\
\text { It is recommended not to delay a curative treatment such as surgery and ablation } \\
\text { Cytoreductive or non-curative treatment such as vascular interventions and systemic therapy may be postponed } \\
\text { For patients with confirmed or suspected to be infected with the novel coronavirus, treatments should be postponed until } \\
\text { the virus is eliminated or they are confirmed as not being infected with it }\end{array}$ \\
\hline Liver resection & $\begin{array}{l}\text { Generally, liver resection with curative intent should not be delayed } \\
\text { However, in cases of high risk of decompensation or comorbidities, surgical intervention should be postponed or alter- } \\
\text { native therapy such as ablation should be adapted } \\
\text { There has been some concern on the safety of surgery as surgery cannot be performed without aerosol generating proce- } \\
\text { dures }\end{array}$ \\
\hline Liver transplantation & $\begin{array}{l}\text { Liver transplantation for patients with poor short-term prognosis should not be delayed } \\
\text { Elective living donor transplantation may be suspended } \\
\text { In patients with complete response to bridging therapy on transplant list, transplantation may be suspended }\end{array}$ \\
\hline Ablation & $\begin{array}{l}\text { Ablation with curative intent should not be delayed } \\
\text { Ablation is an acceptable alternative to resection for cases of three or fewer tumors, each } 3 \mathrm{~cm} \text { or smaller, and of Child- } \\
\text { Pugh class A or B liver dysfunction }\end{array}$ \\
\hline Vascular interventions & $\begin{array}{l}\text { Vascular interventions may be postponed because they are used as cytoreductive treatments in most cases } \\
\text { Vascular interventions should be suspended in cases of risk of decompensation or comorbidities that increase the risk of } \\
\text { severe COVID-19 }\end{array}$ \\
\hline Radiation therapy & $\begin{array}{l}\text { Radiation therapy for cases of symptoms control or at low risk of progression may be postponed } \\
\text { However, radiation therapy for function- or life-threatening situation have to be treated without delay } \\
\text { The course of radiation should be shortened when appropriate }\end{array}$ \\
\hline Systemic therapy & $\begin{array}{l}\text { Oral tyrosine kinase inhibitors would be better than infusional regimens during the pandemic } \\
\text { The impact of immunotherapy on the course of COVID-19 is not known }\end{array}$ \\
\hline
\end{tabular}


There has been some concern on the safety of surgery during COVID-19 pandemic as surgery cannot be performed without aerosol generating procedures, such as endotracheal incubation and energy device usage which produces surgical smoke. Laparoscopic or robotic surgery during the pandemic may contribute to decreased length of stay as compared with open surgery as well as minimizing the need for medical treatments. On the other hand, pneumoperitoneum, which is inevitable in laparoscopic or robotic surgery may bring higher risk of aerosol exposure to the surgeons and staff.

\section{Liver transplantation}

Liver transplantation, which is the best therapeutic option in some patients because it can be a treatment not only for HCC but also for cirrhosis. However, organ donor shortage restricts its indication.

During COVID-19 pandemic, transplantation should be decided on case-by-case basis. Liver transplantation for patients with poor short-term prognosis, such as with high MELD score and HCC at the upper limits of the Milan criteria are in high priority and should not be delayed $[36,37]$ and for those with compensated liver disease and within the lower limits of Milan criteria have medium priority may be suspended to minimize the risk of the donor and the recipient. In patients with complete response to bridging therapy on transplant list, transplantation may also be suspended until it can be performed safely with sufficient resources.

\section{Ablation}

Image-guided percutaneous ablation, such as radiofrequency ablation, microwave ablation and others, are minimally invasive therapies for HCC. Ablation is a potentially curative treatment and easily repeatable for recurrence. Ablation with curative intent should not be delayed. In cases of three or fewer tumors, each $3 \mathrm{~cm}$ or smaller, and of Child-Pugh class A or B liver dysfunction, ablation is an acceptable alternative to resection [38].

Ablation itself is not an aerosol generating procedure (Figs. 1, 2, 3) [39]. Ablation is generally performed with local anesthesia. In some institutions, ablation is performed with general anesthesia, and general anesthesia is an aerosol generating procedure. When general anesthesia is performed, ablation rooms are considered as high-risk areas of infection.

\section{Vascular interventions}

Vascular interventions, such as transarterial chemoembolization and hepatic arterial infusion chemotherapy, are recommended for cases of unresectable, large/multifocal HCCs without vascular invasion nor extrahepatic spread. Vascular interventions are cytoreductive treatments in most cases. Therefore, they may be suspended until they can be performed safely with sufficient resources.

Vascular interventions should be suspended in cases of risk of decompensation or comorbidities that increase the risk of severe COVID-19 because of reduced inpatient beds
Fig. 1 Image-guided percutaneous ablations, such as radiofrequency ablation, microwave ablation and others, are minimally invasive therapies for HCC. Ablation with curative intent should not be delayed even during the COVID-19 pandemic. The patient is in an upright position. An RFA electrode is inserted from the epigastrium into a tumor in the left lateral segment

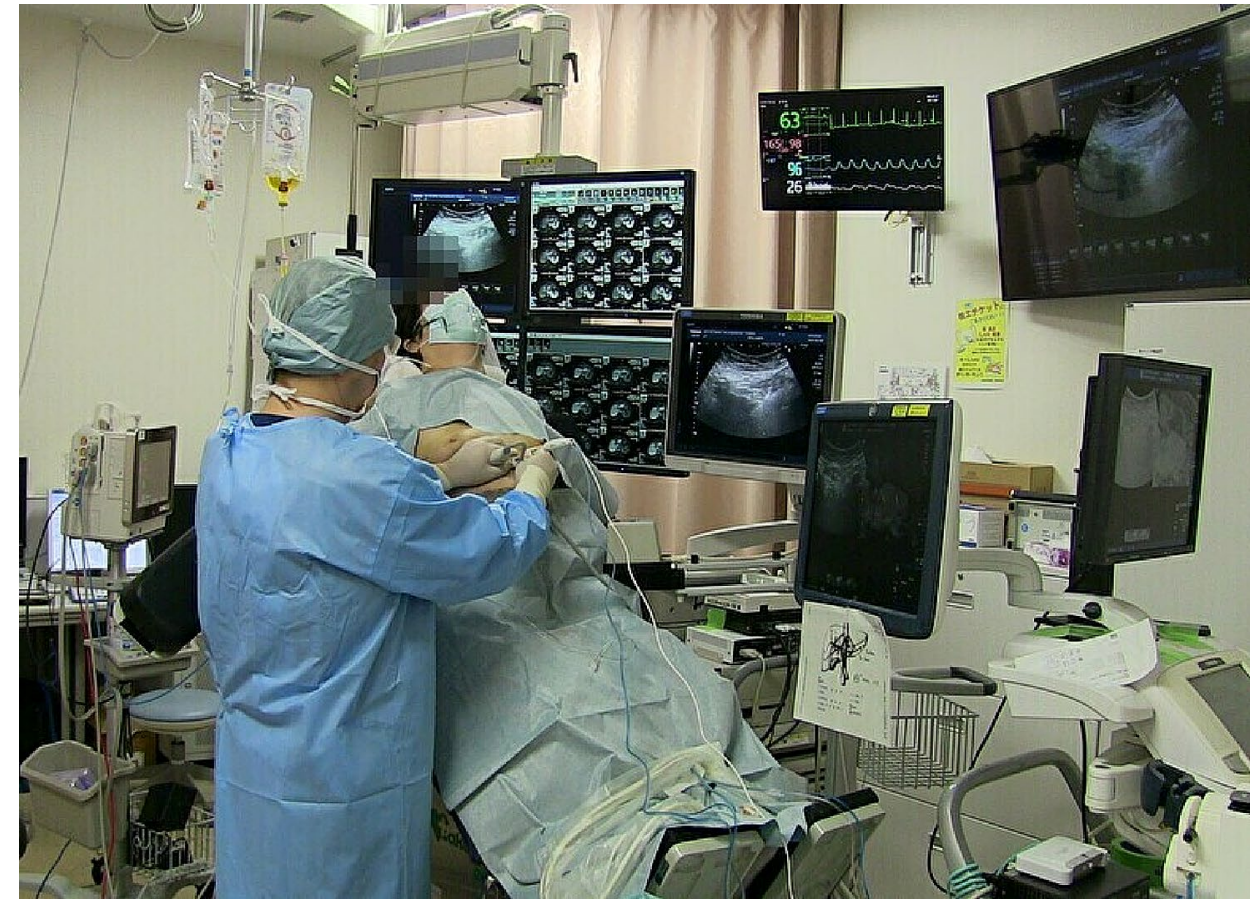




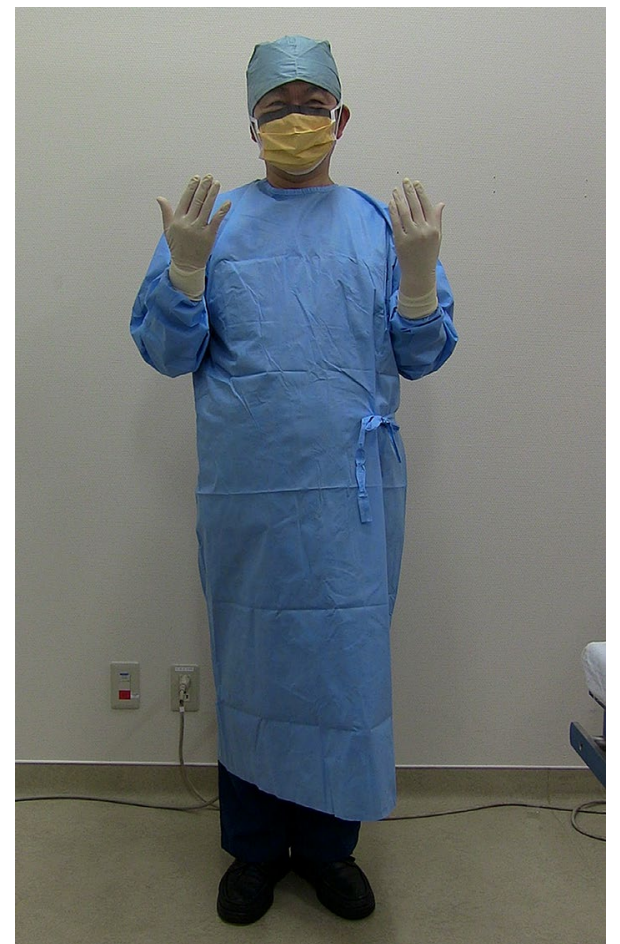

Fig. 2 Personal Protective Equipment (PPE) consists head cover, eye guard, surgical mask, isolation gown, gloves

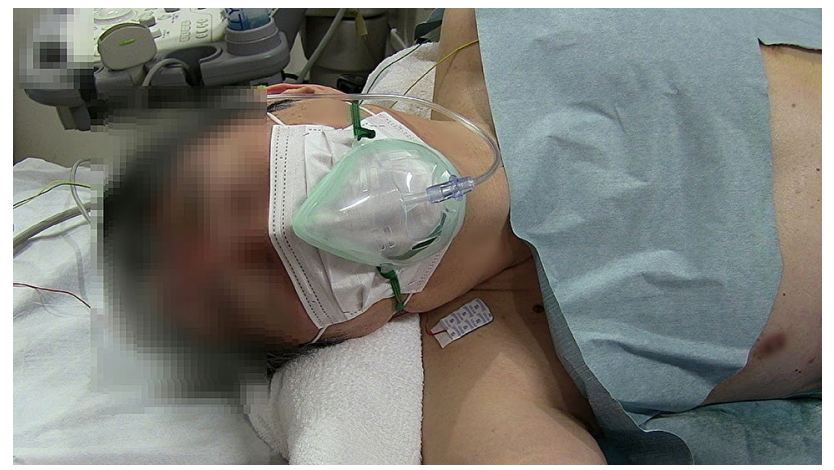

Fig. 3 Patients also should wear facemasks, and oxygen masks should be on top

for post-procedure care. If vascular intervensions are performed, selective or super selective chemoembolization should be attempted to prevent severe postembolization symptoms.

Vascular interventions, themselves are not aerosol generating procedures [39].

\section{Radiation therapy}

Radiation therapy, including proton beam and carbon ion beam therapies, can be used as an option for local control of HCC. Palliative care for cases receiving the therapy to control symptoms or at low risk of progression is better to delay the schedule of radiation [40]. However, radiation therapy for patients with rapidly progressing HCC may outweigh the risks of the novel coronavirus infection. Radiation therapy for function- or life-threatening situation such as spinal cord compression and inferior vena cava syndrome have to be treated without delay. The course of radiation should be shortened, for example, single-fraction treatment for bone pain, and less fractionation when appropriate.

\section{Systemic therapy}

Systemic therapy is for advanced-stage HCC such as with macrovascular invasion or extrahepatic metastasis and with Child-Pugh class A liver function. For cases of advanced HCC treated with systemic therapy, oral tyrosine kinase inhibitors would be better than infusional regimens during the pandemic to protect both patients and medical staff. If available, video call should be used to manage common adverse events. Intravenous chemotherapy should be administered in a dedicated section of outpatient service. The impact of immunotherapy on the course of COVID-19 is not known since there is no sufficient data. Immunotherapy should be considered on a case-by-case basis. Clinical trial recruitment should be suspended until the COVID-19 pandemic settles down. During the COVID-19 pandemic, postponing of locoregional therapies may be necessary. Oral targeted drugs might be a substitute for some patients.

\section{Follow-up for HCC}

It is recommended to follow up the patients by telemedicine or online consultation to minimize hospital visits in the circumstances of COVID-19 pandemic. However, due to its high frequency of the recurrence in HCC, imaging examination to detect recurrence at the early stage should not be postponed.

\section{Conclusions}

In these difficult times, it is our obligation to preserve high management standards of other diseases as well as to effectively handle the COVID-19 pandemic in spite of the shortage of medical resources, such as personnel, beds, PPE and others. To keep our patients and ourselves safe, we should share our experiences and strategies to manage our patients.

The novel coronavirus infection will not settle down in the near future. We need to collect real-world data to mitigate the impact of COVID-19. It is mandatory to collect follow-up data of patients who recovered from COVID-19. There have not been any data available on COVID-19 from 
long-term viewpoint, since COVID-19 was first reported at the end of 2019. It is important to determine the symptomatic and asymptomatic incidence of the novel coronavirus infection by large-scale serological testing not only in the general population but also in patients with $\mathrm{HCC}$ and to survey their COVID-19-related morbidity and mortality to adjust management strategies of $\mathrm{HCC}$.

\section{Compliance with ethical standards}

Conflict of interest Shuichiro Shiina, Rino A. Gani, Osamu Yokosuka, Hitoshi Maruyama, Hiroaki Nagamatsu, Diana Alcantara Payawal, A. Kadir Dokmeci, Laurentius A. Lesmana, Tawesak Tanwandee, George Lau, Shiv Kumar Sarin, Masao Omata have no conflict of interest to declare.

Open Access This article is licensed under a Creative Commons Attribution 4.0 International License, which permits use, sharing, adaptation, distribution and reproduction in any medium or format, as long as you give appropriate credit to the original author(s) and the source, provide a link to the Creative Commons licence, and indicate if changes were made. The images or other third party material in this article are included in the article's Creative Commons licence, unless indicated otherwise in a credit line to the material. If material is not included in the article's Creative Commons licence and your intended use is not permitted by statutory regulation or exceeds the permitted use, you will need to obtain permission directly from the copyright holder. To view a copy of this licence, visit http://creativecommons.org/licenses/by/4.0/.

\section{References}

1. World Health Origanization. Coronavirus disease (COVID-19) Pandemic 2020, April 27. https://www.who.int/emergencies/disea ses/novel-coronavirus-2019. Accessed 9 May 2020

2. Kissler. Projecting the transmission 2020, April 14. https://scien ce.sciencemag.org/content/early/2020/04/24/science.abb5793. Accessed 29 Apr 2020

3. European Society for Medical Oncology. Cancer Patient Management During The COVID-19 Pandemic. 2020. https://www.esmo. org/guidelines/cancer-patient-management-during-the-covid-19pandemic. Accessed 5 May 2020

4. American Society of Clinical Oncology. ASCO Coronavirus Resources. 2020. https://www.asco.org/asco-coronavirus-infor mation. Accessed 5 May 2020

5. European Society for Medical Oncology. ESMO management and treatment adapted recommendations in the COVID-19 era: hepatocelluar carcinoma (HCC). 2020. https://www.esmo.org/guide lines/cancer-patient-management-during-the-covid-19-pande mic/gastrointestinal-cancers-hepatocellular-carcinoma-hcc-inthe-covid-19-era. Accessed 5 May 2020

6. International Liver Cancer Association. Management of HCC during COVID-19: ILCA guidance. 2020. https://ilca-online.org/ management-of-hcc-during-covid-19-ilca-guidance/. Accessed 5 May 2020

7. Boettler T, Newsome PN, Mondelli MU, Maticic M, Cordero E, Cornberg $\mathrm{M}$, et al. Care of patients with liver disease during the COVID-19 pandemic: EASL-ESCMID position paper. JHEP Rep. 2020;2(3):100113. https://doi.org/10.1016/j.jhepr.2020.100113.

8. World Health Origanization. Cancer. 2020. https://www.who.int/ en/news-room/fact-sheets/detail/cancer. Accessed 28 Apr 2020
9. Lozano R, Naghavi M, Foreman K, Lim S, Shibuya K, Aboyans $\mathrm{V}$, et al. Global and regional mortality from 235 causes of death for 20 age groups in 1990 and 2010: a systematic analysis for the Global Burden of Disease Study 2010. Lancet. 2012;380(9859):2095-128. https://doi.org/10.1016/S0140 $-6736(12) 61728-0$.

10. Apasl Covid-19 Task Force, Lau G, Sharma M. Clinical practice guidance for hepatology and liver transplant providers during the COVID-19 pandemic: APASL expert panel consensus recommendations. Hepatol Int. 2020. https://doi.org/10.1007/s12072-02010054-w.

11. European Respiratory Society. COVID-19: Guidelines and recommendations directory. 2020. https://www.ersnet.org/covid-19guidelines-and-recommendations-directory. Accessed 5 May 2020

12. Liang W, Guan W, Chen R, Wang W, Li J, Xu K, et al. Cancer patients in SARS-CoV-2 infection: a nationwide analysis in China. Lancet Oncol. 2020;21(3):335-7. https://doi.org/10.1016/S1470 $-2045(20) 30096-6$.

13. Yu J, Ouyang W, Chua MLK, Xie C. SARS-CoV-2 Transmission in patients with cancer at a tertiary care hospital in Wuhan. China JAMA Oncol. 2020. https://doi.org/10.1001/jamao ncol.2020.0980.

14. Zhang L, Zhu F, Xie L, Wang C, Wang J, Chen R, et al. Clinical characteristics of COVID-19-infected cancer patients: a retrospective case study in three hospitals within Wuhan, China. Ann Oncol. 2020. https://doi.org/10.1016/j.annonc.2020.03.296.

15. Centers for Disease Control and Prevention. People Who Are At Higher Risk. 2020. https://www.cdc.gov/coronavirus/2019-ncov/ need-extra-precautions/liver-disease.html. Accessed 1 June 2020

16. Chen N, Zhou M, Dong X, Qu J, Gong F, Han Y, et al. Epidemiological and clinical characteristics of 99 cases of 2019 novel coronavirus pneumonia in Wuhan, China: a descriptive study. Lancet. 2020;395(10223):507-13. https://doi.org/10.1016/S0140 $-6736(20) 30211-7$.

17. Shi H, Han X, Jiang N, Cao Y, Alwalid O, Gu J, et al. Radiological findings from 81 patients with COVID-19 pneumonia in Wuhan, China: a descriptive study. Lancet Infect Dis. 2020;20(4):425-34. https://doi.org/10.1016/S1473-3099(20)30086-4.

18. Guan WJ, Ni ZY, Hu Y, Liang WH, Ou CQ, He JX, et al. Characteristics of coronavirus disease 2019 in China. N Engl J Med. 2020. https://doi.org/10.1056/NEJMoa2002032.

19. Huang C, Wang Y, Li X, Ren L, Zhao J, Hu Y, et al. Clinical features of patients infected with 2019 novel coronavirus in Wuhan, China. Lancet. 2020;395(10223):497-506. https://doi. org/10.1016/S0140-6736(20)30183-5.

20. Wang D, Hu B, Hu C, Zhu F, Liu X, Zhang J, et al. Clinical characteristics of 138 hospitalized patients with 2019 novel coronavirus-infected pneumonia in Wuhan China. JAMA. 2020. https ://doi.org/10.1001/jama.2020.1585.

21. Xu XW, Wu XX, Jiang XG, Xu KJ, Ying LJ, Ma CL, et al. Clinical findings in a group of patients infected with the 2019 novel coronavirus (SARS-Cov-2) outside of Wuhan, China: retrospective case series. BMJ. 2020;368:m606. https://doi.org/10.1136/ bmj.m606.

22. Yang X, Yu Y, Xu J, Shu H, Xia J, Liu H, et al. Clinical course and outcomes of critically ill patients with SARS-CoV-2 pneumonia in Wuhan, China: a single-centered, retrospective, observational study. Lancet Respir Med. 2020. https://doi.org/10.1016/S2213 -2600(20)30079-5.

23. Ji D, Qin E, Xu J, Zhang D, Cheng G, Wang Y, et al. Nonalcoholic fatty liver diseases in patients with COVID-19: a retrospective study. J Hepatol. 2020. https://doi.org/10.1016/j. jhep.2020.03.044.

24. Xu Z, Shi L, Wang Y, Zhang J, Huang L, Zhang C, et al. Pathological findings of COVID-19 associated with acute respiratory 
distress syndrome. Lancet Respir Med. 2020;8(4):420-2. https:// doi.org/10.1016/S2213-2600(20)30076-X.

25. Kumar D, Tellier R, Draker R, Levy G, Humar A. Severe Acute Respiratory Syndrome (SARS) in a liver transplant recipient and guidelines for donor SARS screening. Am J Transpl. 2003;3(8):977-81. https://doi.org/10.103 4/j.1600-6143.2003.00197.x.

26. The Royal College of Radiologists. Statement on use of CT chest to screen for COVID-19 in pre-operative patients. 2020. https:// www.rcr.ac.uk/college/coronavirus-covid-19-what-rcr-doing/clini cal-information/statement-use-ct-chest-screen-covid. Accessed 5 May 2020

27. American College of Radiology. ACR Recommendations for the use of Chest Radiography and Computed Tomography (CT) for Suspected COVID-19 Infection. 2020. https://www.acr.org/Advoc acy-and-Economics/ACR-Position-Statements/Recommendations -for-Chest-Radiography-and-CT-for-Suspected-COVID19-Infec tion. Accessed 6 May 2020

28. American Institute Of Ultrasound In Medicine. Quick Guide on COVID-19 Protections-Patient and Ultrasound Provider Protection. 2020. https://aium.s3.amazonaws.com/covid19/Covid 19_Quick_Guide_PUPP.pdf. Accessed 29 Apr 2020.

29. World Federation for Ultrasound in M, Biology Safety C, Abramowicz JS, Basseal JM. World federation for ultrasound in medicine and biology position statement: how to perform a safe ultrasound examination and clean equipment in the context of COVID-19. Ultrasound Med Biol. 2020. https://doi.org/10.1016/j.ultrasmedb io.2020.03.033.

30. Omata M, Cheng AL, Kokudo N, Kudo M, Lee JM, Jia J, et al. Asia-Pacific clinical practice guidelines on the management of hepatocellular carcinoma: a 2017 update. Hepatol Int. 2017;11(4):317-70. https://doi.org/10.1007/s12072-017-9799-9.

31. The Royal College of Surgeons of England. updated intercollegiate general surgery guidance on COVID-19. 2020. https:// www.rcseng.ac.uk/coronavirus/joint-guidance-for-surgeons-v2/. Accessed 6 May 2020

32. Hirotsu YMM, Nakajima M, Mochizuki H, Omata M. Environmental cleaning is effective for the eradication of severe acute respiratory syndrome coronavirus 2 (SARS-CoV-2) in contaminated hospital rooms: a patient from the diamond princess cruise ship. Infect Control Hosp Epidemiol. 2020. https://doi.org/10.1017/ ice.2020.144.
33. American College of Surgeons. COVID-19: Guidance for triage of non-emergent surgical procedures. 2020. https://www.facs.org/ covid-19/clinical-guidance/triage. Accessed 6 May 2020

34. World Health Origanization. Rational use of personal protective equipment (PPE) for coronavirus disease (COVID-19) World Health Origanization. 2020. https://apps.who.int/iris/bitstream/ handle/10665/331498/WHO-2019-nCoV-IPCPPE_use-2020.2eng.pdf. Accessed 6 May 2020

35. Royal College of Surgeons of England. Updated Intercollegiate General Surgery Guidance on COVID-19. 2020. https:// www.rcseng.ac.uk/coronavirus/joint-guidance-for-surgeons-v2/. Accessed 17 May 2020

36. Saigal S, Gupta S, Sudhindran S, Goyal N, Rastogi A, Jacob M, et al. Liver transplantation and COVID-19 (Coronavirus) infection: guidelines of the liver transplant Society of India (LTSI). Hepatol Int. 2020. https://doi.org/10.1007/s12072-020-10041-1.

37. Liu H, He X, Wang Y, Zhou S, Zhang D, Zhu J, et al. Management of COVID-19 in patients after liver transplantation: Beijing working party for liver transplantation. Hepatol Int. 2020. https:// doi.org/10.1007/s12072-020-10043-z.

38. Izumi N, Hasegawa K, Nishioka Y, Takayama T, Yamanaka N, Kudo M, et al. A multicenter randomized controlled trial to evaluate the efficacy of surgery vs radiofrequency ablation for small hepatocellular carcinoma (SURF trial). J Clin Oncol. 2019;37(15_ suppl):4002-4002. https://doi.org/10.1200/JCO.2019.37.15_suppl .4002 .

39. National Health Service England. Aerosol generating procedures. May 6. 2020. https://www.england.nhs.uk/coronavirus/primarycare/infection-control/aerosol-generating-procedures/. Accessed 6 May 2020

40. American Society for Radiation Oncology. COVID-19 recommendations and information. 2020. https://www.astro.org/Daily -Practice/COVID-19-Recommendations-and-Information/Summa ry. Accessed 6 May 2020

Publisher's Note Springer Nature remains neutral with regard to jurisdictional claims in published maps and institutional affiliations.

\section{Affiliations}

\section{Shuichiro Shiina ${ }^{1}$ (D) Rino A. Gani ${ }^{2} \cdot$ Osamu Yokosuka $^{3} \cdot$ Hitoshi Maruyama ${ }^{1} \cdot$ Hiroaki Nagamatsu' ${ }^{1}$. Diana Alcantara Payawal ${ }^{4} \cdot$ A. Kadir Dokmeci ${ }^{5}$. Laurentius A. Lesmana ${ }^{6} \cdot$ Tawesak Tanwandee $^{7} \cdot$ George Lau $^{8,9}$. Shiv Kumar Sarin ${ }^{10} \cdot$ Masao Omata $^{11,12}$}

\author{
Rino A. Gani \\ personaly@yahoo.com \\ Osamu Yokosuka \\ yokosukao@faculty.chiba-u.jp \\ Hitoshi Maruyama \\ h.maruyama.tw@juntendo.ac.jp \\ Hiroaki Nagamatsu \\ h-nagamatsu@juntendo.ac.jp \\ Diana Alcantara Payawal \\ dianapayawal@yahoo.com \\ A. Kadir Dokmeci \\ akdokmeci@hotmail.com
}

Laurentius A. Lesmana

llesmana.id@gmail.com

Tawesak Tanwandee

tawesak@gmail.com

George Lau

gkklau@netvigator.com; gkklau@hnhmgl.com

Shiv Kumar Sarin

shivsarin@gmail.com

Masao Omata

aug8808@yahoo.co.jp

1 Department of Gastroenterology, Juntendo University, 2-1-1, Hongo, Bunkyo-ku, Tokyo 113-8421, Japan 
2 Department of Internal Medicine, Cipto Mangunkusumo Hospital, University of Indonesia, Jakarta, Indonesia

3 Chiba University, Chiba, Japan

4 Department of Hepatology, Cardinal Santos Medical Center, Manila, Philippines

5 Department of Gastroenterology, Ankara University School of Medicine, Ankara, Turkey

6 Digestive Disease and GI Oncology Center, Medistra, Hospital, University of Indonesia, Jakarta, Indonesia

7 Department of Medicine, Faculty of Medicine, Siriraj Hospital, Mahidol University, Bangkok, Thailand
8 Humanity and Health Clinical Trial Center, Humanity and Health Medical Group, Hong Kong SAR, China

9 Liver Disease and Transplant Center, The Fifth Medical Center of Chinese PLA General Hospital, Beijing, China

10 Department of Hepatology, Institute of Liver and Biliary Sciences, New Delhi 110070, India

11 Department of Gastroenterology, Yamanashi Prefectural Central Hospital, Kofu-city, Yamanashi, Japan

12 The University of Tokyo, Tokyo, Japan 